\title{
HIV knowledge, risk perception, and safer sex practices among female sex workers in Port Moresby, Papua New Guinea
}

This article was published in the following Dove Press journal:

International Journal of Women's Health

I4 February 201I

Number of times this article has been viewed

\author{
Eunice Bruce' \\ Ludwina Bauai² \\ Mathias Sapuri ${ }^{3}$ \\ John M Kaldor ${ }^{4}$ \\ Christopher K Fairley' \\ Louise A Keogh \\ 'Melbourne Sexual Health Centre, \\ School of Population Health, \\ The University of Melbourne, VIC, \\ Australia; ${ }^{2}$ Central Papua Mission \\ (CPM) of the Seventh Day Adventist \\ Church, Pacific Adventist University, \\ Port Moresby, Papua New Guinea; \\ ${ }^{3}$ Pacific International Hospital, \\ Port Moresby, Papua New Guinea; \\ ${ }^{4}$ National Centre in HIV Epidemiology \\ and Clinical Research, University \\ of New South Wales, Sydney, NSW, \\ Australia; ${ }^{5}$ Centre for Women's \\ Health, Gender and Society, School \\ of Public Health, The University \\ of Melbourne, VIC, Australia
}

\begin{abstract}
Sex workers are considered a high-risk group for sexually transmitted infections, including human immunodeficiency virus (HIV), and are often targeted by prevention interventions with safer sex messages. The purpose of this study was to explore the extent to which knowledge of HIV and perception of risk influence safer sex practices among female sex workers (FSWs) in Port Moresby, Papua New Guinea. FSWs $(n=174)$ were recruited from 19 sites to participate in the study. Qualitative data were collected using semistructured interviews with FSWs $(n=142)$ through focus group discussions and $(n=32)$ individual interviews. In addition, quantitative data were collected from all FSWs using a short structured, demographic questionnaire. Data were analyzed using recurring themes and calculations of confidence intervals. Despite some common misperceptions, overall, most FSWs were basically aware of the risks of HIV and informed about transmission and prevention modalities but used condoms inconsistently. Most reported using condoms 'sometimes', almost one-sixth 'never' used condoms, only a fraction used condoms 'always' with clients, and none used condoms 'always' with regular sexual partners (RSPs). Among these FSWs, being knowledgeable about the risks, transmission, and prevention of HIV did not translate into safe sex. The findings suggest that certain contextual barriers to safer sex practices exist. These barriers could heighten HIV vulnerability and possibly may be responsible for infection in FSWs. Specific interventions that focus on improving condom self-efficacy in FSWs and simultaneously target clients and RSPs with safer sex messages are recommended.
\end{abstract}

Keywords: HIV knowledge, risk perception, safer sex practices, female sex workers, clients, regular sexual partners

\section{Introduction}

Papua New Guinea (PNG) has one of the most rapidly growing human immunodeficiency virus (HIV) epidemics in the Asia Pacific Region, with heterosexual transmission accounting for an increasing fraction of all new infections. ${ }^{1}$ In PNG, as in many developing countries, unsafe sex is the primary mode of HIV transmission. ${ }^{2}$ In these settings, young females, especially female sex workers (FSWs), are the first group to be observed with the virus and disproportionately affected. ${ }^{2,3}$ In 1998, in PNG, a study of 407 FSWs in Port Moresby and Lae reported an HIV prevalence of 17\% (34 of 205). ${ }^{4}$ At the same time, the prevalence among pregnant women was $0.37 \%$ and among the adult population in the entire country was $0.19 \% .{ }^{1}$ In 2004 , the prevalence of the HIV infection nearly quadrupled to $1.4 \%$ in pregnant women compared with $0.37 \%$ in 1998.5 However, more recent data indicate that the prevalence of HIV infection has risen nearly by seven-fold to $1.5 \%$ within the general population compared with $0.19 \%$ in $1998 .^{6}$
Correspondence: Eunice Bruce Melbourne Sexual Health Centre, School of Population Health, The University of Melbourne, VIC 3053, Australia

Tel +6I 45I 568208

Fax +6I 393476757

Email ebruce@mshc.org.au 
Of the 407 FSWs surveyed, 85\% reported not to have used condoms consistently with their clients, $34 \%$ reported never to have used condoms, and only $9 \%$ always used condoms with their regular sexual partners (RSPs). ${ }^{4}$ These findings are reported consistently for PNG. ${ }^{7-11}$ Due to such risky sexual behaviors, it is widely perceived that FSWs will play a significant role in the HIV epidemic in PNG. ${ }^{12,13}$

As the debate on the role of FSWs in HIV transmission intensifies in PNG, the role of clients and RSPs of FSWs in HIV transmission has been grossly overlooked. A study in 1994 reported that clients of FSWs were a mixture of $23 \%$ single, $3 \%$ widowed, and $74 \%$ married men. The profiles of the clients consistently reported, among others, ${ }^{4,8}$ were policemen, soldiers, electricians, government employees, loggers, miners, managers of businesses and agricultural stations, sailors, truckers, and security guards. ${ }^{9}$ So far there are few or no data on the social and behavioral characteristics of clients and RSPs of FSWs. In PNG, FSWs themselves refer to their clients and other sexual partners with terms that designate how well they know them and how regular they are as sexual partners. In general terms, they refer to clients as men who buy or pay for sex, locally known as 'K-pap' or 'pumuk man'. ' They also refer to RSPs as steady, noncommercial partners/boyfriends, ${ }^{4,8,9}$ locally known as 'lewa' (liver or heart) or 'wantoks'. ${ }^{9}$ In 1994, an ethnography study reported that RSPs comprise married men who may have other sexual partners but according to FSWs are highly valued partners because they are gentle in their ways, make enjoyable sexual partners, and provide emotional support. ${ }^{9}$ Although there are no data describing how long relationships between FSWs and RSPs tend to last, available data show that RSPs are not pimps. ${ }^{9}$ Disturbingly though, these studies have reported low and inconsistent condom use among FSWs with their clients and RSPs., ${ }^{4,8}$

To date, condoms remain the single most effective means to reduce the transmission of sexually transmitted infections (STIs) ${ }^{14}$ and to protect against HIV. ${ }^{15}$ In FSWs, a number of studies have shown an association between increased condom use and declined rates of STIs, including new HIV infections. ${ }^{16,17}$ Even though the production and distribution of condoms have increased worldwide ${ }^{18}$ and safer sex messages continue to reach FSWs through social marketing, behavior change communication strategies, and public health policies, ${ }^{3}$ these efforts have not always resulted in consistent condom use. . $^{8,19,20}$

In an attempt to explain this outcome, a number of researchers have suggested that condom use in FSWs is determined by the social context within which the sexual behavior occurs. ${ }^{19,21,22}$ In resource-constrained settings, researchers have found that certain intrinsic factors act as 'barriers' rather than 'enablers' to safer sex practices. ${ }^{21,23-25}$ These barriers include underdevelopment/poverty, ${ }^{24,26}$ gender inequalities/cultural norms, ${ }^{27,28}$ knowledge/risk perception, ${ }^{29,30}$ negotiation ability/self-efficacy, ${ }^{8,22}$ and other aspects of the environment. ${ }^{21,31}$

In the quest to understand the determinants of risky sexual behavior among FSWs in Port Moresby, this article reports on a study that explored HIV knowledge and risk perception and how these translated into safer sex practices. We aimed to document the practical barriers to safe sex practices and contribute to programming decisions and HIV policy.

\section{Methods}

This study is the sixth component of a large United Nations Population Fund (UNFPA) operational research grant to the project on comprehensive models of STI/HIV/AIDS prevention for sex workers and their clients in the Asia Pacific region. Details of the program funded by the grant have been reported elsewhere. ${ }^{32}$ This qualitative study reports on an in-depth assessment of the HIV situation among FSWs in Port Moresby. We report here on HIV knowledge, risk perception, sexual behaviors, and safe sex practices among FSWs. The study was carried out between April and June 2004. As part of the UNFPA grant, a mapping and size estimation exercise was conducted earlier in $2003 .{ }^{33}$ The exercise identified the locations where FSWs solicited their clients in Port Moresby. Examples of the locations included guest houses, wharves, urban villages, and settlements. The data reported here were collected from FSWs across these locations as part of an existing HIV project.

FSWs from our earlier studies, existing HIV projects, and new referrals were recruited to participate in the study. The new referrals were recruited using peer-mediated contact. Participation was voluntary, and those who agreed by verbal consent were fully briefed about the study objectives and procedures. Participants were eligible if they were aged 14 years and older and had sold sex for money or goods in the previous month. Participants then chose to take part in either a focus group discussion (FGD) or an individual interview. They were also asked to complete a short structured questionnaire where sociodemographic data were obtained. In this study, a RSP refers to a steady, noncommercial sexual partner or a steady, nonpaying boyfriend of a FSW.

Participants who chose to take part in an interview were interviewed at a time and location convenient to them. The interview was semistructured with open-ended questions on 
HIV knowledge, perceived risk, and safe sex. For those who chose to take part in an FGD, a facilitator and two researchers facilitated the sessions of up to $10 \mathrm{FSWs}$ per group. The same open-ended questions were employed as those used in individual interviews. Interviewers and facilitators were female. A tape recorder was used, and participants were assured that they could turn it off at any time should they become anxious. The interviews and discussions were conducted in local pidgin and lasted about $90 \mathrm{~min}$. Information was recorded verbatim, translated, summarized, and reviewed together with participants for accuracy.

The interview and focus group data were analyzed together. Thematic analysis was used to identify recurring themes. The data in each theme were then contrasted and compared in order to identify commonly held correct perceptions and misperceptions about HIV/STI, risk perception, sexual practices, and barriers and enablers to implementing safe sex. For each behavior that we were interested in, the full range of practices was identified and, where possible, FSWs were allocated to a practice group. Data from the short structured questionnaire were entered, converted, and confidence intervals for proportions analyzed using Confidence Interval Analysis (CIA) version 1.0 (Statistics with Confidence, London, UK). The study was approved by the Research Committee of the School of Medicine and Health Sciences, University of PNG (UPNG), and the Medical Research Advisory Committee, National Department of Health, PNG.

\section{Results}

A total of $174 \mathrm{FSWs}$ from 19 locations participated in a total of 16 FGD $(n=142,82 \%)$ and 32 in-depth interviews $(n=32$, 18\%). Table 1 shows the sociodemographic characteristics of the FSWs. They ranged from 14 to 44 years old, with the largest groups comprising FSWs in their most productive years (14-20 and 21-30). The majority of FSWs were divorced, poorly educated, exclusively sold sex for a living, and had engaged in sex work for more than 3 years. More than half had RSPs. Table 2 shows HIV/STI knowledge, condom use, and risk perceptions of the FSWs. All FSWs had heard of HIV/ AIDS, and 98\% were adequately informed about HIV transmission through sexual contact. Almost three-quarters were aware that condoms are the most effective means of preventing HIV, but condom use with clients was 'sometimes' $79 \%$ (95\% CI: 73-85), 'never' 15\% (95\% CI: 10-21), and 'always' $6 \%$ (95\% CI: 3-11). Condom use with RSPs was 'sometimes' 18\% (95\% CI: 12-24), 'never' $82 \%$ (95\% CI: 93-99), and 'always' 0\% (95\% CI: 0-02). Each FSW had an average of three condoms at hand during the FGD and knew where to
Table I Sociodemographic characteristics of FSWs in Port Moresby $(n=174)$

\begin{tabular}{|c|c|c|}
\hline Characteristics & $\begin{array}{l}\% \text { or } \\
\text { (mean) }\end{array}$ & $\begin{array}{l}95 \% \mathrm{Cl} \\
\text { or range }\end{array}$ \\
\hline \multicolumn{3}{|l|}{ Age (years) } \\
\hline $14-20$ & 36.0 & $29-43$ \\
\hline $21-30$ & 32.0 & $25-39$ \\
\hline $31-40$ & 19.0 & $21-25$ \\
\hline $4 I-50$ & 13.0 & $8-18$ \\
\hline \multicolumn{3}{|l|}{ Education } \\
\hline None & 30.0 & - \\
\hline Primary & 70.0 & - \\
\hline \multicolumn{3}{|l|}{ Marital status } \\
\hline Single & 24.0 & - \\
\hline Married & 35.0 & - \\
\hline Divorced & 41.0 & - \\
\hline \multicolumn{3}{|l|}{ Current boyfriend/RSPs status } \\
\hline With current RSPs & 64.0 & - \\
\hline Without current RSPs & 36.0 & - \\
\hline Religion (Christian) & 100 & - \\
\hline No. of children/FSW (mean) & (2) & $1-4$ \\
\hline \multicolumn{3}{|l|}{ Living arrangements } \\
\hline Alone & 33.0 & - \\
\hline Friends & 24.0 & - \\
\hline Relatives & 18.0 & - \\
\hline Protectors (guards of FSWs) & 12.0 & - \\
\hline Shared guest house with peers & 7.0 & - \\
\hline Parents & 6.0 & - \\
\hline \multicolumn{3}{|l|}{ Income besides sex work } \\
\hline No & 75.0 & - \\
\hline Yes & 25.0 & - \\
\hline \multicolumn{3}{|l|}{ Place of sex work } \\
\hline Port Moresby only & 52.0 & - \\
\hline Outside Port Moresby & 48.0 & - \\
\hline \multicolumn{3}{|l|}{ Years engaged in sex work } \\
\hline $1-3$ years & 32.0 & $25-39$ \\
\hline 4-6 years & 28.0 & $21-34$ \\
\hline $7-9$ & 21.0 & $15-27$ \\
\hline 10 and above & 18.0 & $14-25$ \\
\hline No. specific years (on and off)' & 1.0 & $0.2-3$ \\
\hline
\end{tabular}

Note: 'One person did not fit.

Abbreviations: FSWs, female sex workers; $\mathrm{Cl}$, confidence interval; RSPs, regular sexual partners.

obtain them at no cost. The most frequently reported reasons for not using condoms included clients' dislike (40\%), trust (35\%), and inability to negotiate (22\%). Most FSWs perceived themselves at risk of HIV; however, most believed that their chances of getting infected were higher through sex work than through their private sexual relationships.

\section{HIV/STI knowledge}

\section{Widely held correct perceptions}

Participants were asked whether they had heard of HIV/STIs and, if so, how they were transmitted and prevented; whether they could tell if someone had the virus; and whether they believed HIV was curable. Data from FGD and interviews 
Table 2 HIV/STI knowledge, condom use, and risk perceptions of FSWs in Port Moresby $(n=174)$

\begin{tabular}{|c|c|c|}
\hline Characteristics & $\begin{array}{l}\text { \% or } \\
\text { (mean) }\end{array}$ & $\begin{array}{l}95 \% \mathrm{Cl} \\
\text { or range }\end{array}$ \\
\hline \multicolumn{3}{|l|}{ HIV knowledge } \\
\hline Heard of HIV & 100 & $98-100$ \\
\hline $\begin{array}{l}\text { Aware HIV is transmitted through } \\
\text { sexual contacts }\end{array}$ & 98.0 & $95-97$ \\
\hline Aware condom use prevents HIV & 70.0 & $63-76$ \\
\hline \multicolumn{3}{|l|}{ Condom use } \\
\hline Condom use with clients 'always' & 6.0 & $3-11$ \\
\hline Condom use with clients 'sometimes' & 79.0 & $73-85$ \\
\hline Condom use with clients 'never' & 15.0 & $|0-2|$ \\
\hline Condom use with RSPs 'always' & 0.0 & $0-2$ \\
\hline Condom use with RSPs 'sometimes' & 18.0 & $12-24$ \\
\hline Condom use with RSPs 'never' & 82.0 & $93-99$ \\
\hline $\begin{array}{l}\text { No. of condoms in possession } \\
\text { during interview (mean) }\end{array}$ & (3) & $4-5$ \\
\hline \multicolumn{3}{|l|}{ Reasons for inconsistent condom use } \\
\hline Client dislike/refusal & 40.0 & $33-48$ \\
\hline Trust & 35.0 & $28-42$ \\
\hline Unable to negotiate use & 22.0 & $16-28$ \\
\hline Inconvenient to use & 3.0 & $1-7$ \\
\hline \multicolumn{3}{|l|}{ STI knowledge } \\
\hline Heard of STls & 72.0 & $65-79$ \\
\hline Heard of gonorrhea & 70.0 & $63-77$ \\
\hline Syphilis & 68.0 & $61-75$ \\
\hline Chlamydia & 25 & $19-32$ \\
\hline Trichomonas & 12 & $7-17$ \\
\hline Had STI treatment in the last & 83 & $77-88$ \\
\hline \multicolumn{3}{|l|}{12 months } \\
\hline Vaginal discharge an STI symptom & 32 & $25-39$ \\
\hline Vaginal itch an STI symptom & 27 & $20-34$ \\
\hline $\begin{array}{l}\text { Lower abdominal pain an STI } \\
\text { symptom }\end{array}$ & II & $6-16$ \\
\hline \multicolumn{3}{|l|}{ Risk perceptions } \\
\hline $\begin{array}{l}\text { Chance of catching HIV } \\
\text { from client }\end{array}$ & 69 & $62-76$ \\
\hline Chance of catching from RSPs & 31 & $24-38$ \\
\hline
\end{tabular}

Abbreviations: FSWs, female sex workers; Cl, confidence interval; RSPs, regular sexual partners; STI, sexually transmitted infection.

revealed that the majority of FSWs had heard of HIV. One FSW said: "Everywhere you go, people are talking about HIV/AIDS - who does not know about it?" Another one said: "It is in the pamphlets peer educators give us. I have heard so much about HIV". They were aware that HIV is transmissible through sexual contact and pregnant mothers to unborn children. Most FSWs correctly identified condoms as the most effective means of preventing transmission. Several FSWs interjected: "Peer educators give plenty of condoms and say condoms stop HIV". Another said: "Yes, I even have some here". "Me too" concurred a number of FSWs. They were also aware of other prevention methods such as abstinence and being faithful to one uninfected sexual partner. One FSW said: "But how do these methods suit sex workers?
I think they are unrealistic". Most FSWs agreed. In addition, they were aware that HIV is incurable.

Data also revealed that most FSWs interviewed had very basic knowledge about STIs. Most had heard of Neisseria gonorrhea and Treponema pallidum (syphilis), but very few cited Chlamydia trachomatis and Trichomonas vaginalis as other STIs. They were aware that STIs can be transmitted through unprotected sex and are preventable and treatable.

\section{Widely held misperceptions}

On the other hand, most had limited knowledge about HIV transmission through blood contact. Very few mentioned blood transfusion as a mode of transmission, and none was aware of HIV transmission through the sharing of infected needles or injecting drug use. One FSW showed her lack of knowledge by asking: "Could anyone explain to me how this is so?" Some believed the virus could be transmitted through a curse or a mosquito bite, and others believed that it was possible to tell if someone had the virus. As one FSW said: "Sometime, I hear people say HIV is a curse on bad people, the medicine man can cast the spell", another one said: "HIV people look skinny, pale, and have pimples plenty". Some believed that seeking prompt treatment when sick, washing the genitals soon after ejaculation with an antiseptic household cleaner, and getting married could prevent HIV transmission. One FSW confidently stated: "Once I get married, it means no more sex with clients and therefore no gat HIV". Although she believed that sexual intercourse with multiple sexual partners increased HIV risk, somehow she had misperceived that sexual intercourse with one partner would protect her against the virus.

Common STIs such as Candida albicans (thrush), herpes simplex virus (HSV), genital warts, bacterial vaginosis, and Haemophilus ducreyi (chancroid), for instance, were virtually unheard of by most FSWs. Over three-quarters stated that they had received STI treatment at least once in the past, yet they were generally not aware of the symptoms associated with these infections. Most had limited knowledge about the role of STIs in HIV transmission and the value of the use of lubricants with condoms. An FSW probed: "No one has said this to me. This is new to me, but how?" In relation to lubricant, another one said: "em same like oil", implying that the use of oil is equally good.

\section{Risk perception}

Participants were asked about their perception of HIV risk and how they perceived this risk in both sex work and their private sexual relationships. They were also asked about risk in relation to marijuana and alcohol use. 
Data revealed that although most FSWs were aware of HIV risk through sexual contacts, most perceived themselves as more at risk of infection through sex work than through their private sexual relationships. Almost all FSWs misperceived that sexual intercourse with RSPs posed low risk compared with intercourse with clients. One FSW said: "Clients sleep with so many people. They can pick up anything and bring to me, but RSPs are not like that". Most FSWs were unable to identify the links between marijuana/alcohol use and HIV risk. One FSW asked: "What has marijuana or alcohol got to do with HIV? I see no obvious connection".

\section{Sexual behaviors and practices}

Participants were asked about their most recent sexual encounter and asked whether they used condoms consistently with clients and RSPs.

Data revealed most FSWs had recently engaged in unsafe sex with clients and RSPs despite adequate knowledge. Although most FSWs perceived themselves as more at risk of infection through sex work, condom use with clients was low and inconsistent. Of those who had RSPs, about one-tenth reported to have used condoms 'sometimes', about threequarters reported 'never' to have used condoms, and none reported to have used them 'always', indicating an overall consistent use of condoms with RSPs to be virtually nonexistent. A representative statement made by a FSW during the FGD was: "I do not think my boyfriend will intentionally give me HIV".

\section{Barriers and enablers of safer sex practices}

Participants were asked about safer sex practices and what they believed were the enablers and challenges in consistent safe sex practice.

\section{Enablers to implementing knowledge}

Data revealed that most FSWs believed that safe sex $(100 \%$ condom use at all times) is useful and must continue irrespective of its challenges. Data from the short questionnaire also revealed that each FSW had an average of three condoms at hand and during the FDG sessions claimed to carry them at all times. All FSWs knew where to obtain them at no cost from their peer educators, the National AIDS Council, and other aid agencies.

\section{Practical barriers to implementing knowledge}

Most FSWs recognized that prevention means, such as abstinence and being faithful to one sexual partner, were unrealistic for sex workers. Although few FSWs (3\%) felt that condom use was inconvenient and took the fun out of sex, about one-third (35\%) cited trust, an 'emotional factor', as the main reason for sex without condoms with RSPs. About half ( $40 \%$ ) cited clients' refusal as another reason for engaging in unsafe sex. The single most important factor that stood out was the fear of losing an economic benefit should they try to insist on condom use. Twenty-two percent felt they were unable to negotiate condom use, reflecting contextual factors placing FSWs in a weak position to negotiate safe sex. Among these FSWs, a combination of emotional, economic, social, and/or environmental factors served as important practical barriers to safe sex. During the FGD sessions, one sex worker stated: "Our clients know we are desperate for money, so if they refuse condoms and offer extra cash, it is a proposal I can hardly refuse". Another one stated: "At times, I am so broke and need money to survive, I gat no choice". Most FSWs used marijuana, alcohol, and other potent homemade stimulant 'home brews'. Nearly all FSWs who use these substances reported to have had sex under the influence of one or a combination of them but saw no obvious links with HIV risk.

\section{Discussion}

In this qualitative study of FSWs in Port Moresby, we were interested in the disparities between knowledge and sexual practices. We wanted to document in detail what FSWs knew, how it translated into safer sex practices, where their knowledge was poor, and what they identified as practical barriers and enablers to safer sex. We found that although the majority of FSWs were adequately informed about HIV transmission through sexual intercourse and prevention through condom use, this knowledge rarely translated into safer sex practices. The findings suggest that significant barriers to the practice of safe sex confront FSWs, an observation that has been reported elsewhere. ${ }^{19,22}$ In resource-constrained settings, adequate knowledge and risk perception alone may be insufficient to implement safer sex practices. In this article, we discuss the implications of contextual barriers to safe sex in the context of sex work. In PNG, these may be responsible for the spread of HIV among FSWs.

Studies on the influence of HIV knowledge on safer sex practice have reported mixed results. Although some have found conclusive associations, ${ }^{34-36}$ others have found mixed results $^{37,38}$ consistent with our findings. Although some studies found association between individual perception of HIV risk and safer sex practices, ${ }^{39,40}$ others have found mixed results ${ }^{41,42}$ consistent with our findings. This implies that safer sex is complex and determined by several factors in different 
settings. In this study, several factors acted as barriers for FSWs to implement safer sex knowledge. There are a number of possible explanations for this outcome. It may reflect a lack of ability of FSWs to assess risk and apply knowledge during a sexual encounter. ${ }^{30,43}$ All sexual decision making involves the weighing up of a number of risks, where some risks will be accepted and others will not be accepted. ${ }^{44}$ It may also imply that safer sex knowledge and the dynamics of sexual behavior are two different phenomena, neither of which necessarily influences the other when the sexual encounter is being contemplated. ${ }^{45,46}$ It may reflect a sexual behavior that lies within the economic and sociocultural contexts of FSWs, an observation that has been made elsewhere. ${ }^{19-21,23,27}$ The majority of FSWs in our study felt compelled to accept additional cash for unsafe sex with clients who refused to use condoms. Here, economic deprivation limited the ability to resist unsafe sex and increased the ability to make unhealthy choices when the fear of losing a paying client and the economic benefit was imminent. In an environment that offers fewer economic choices for FSWs, economic deprivation is likely to influence risky sexual behaviors and heighten exposure to HIV infection. . $12,24,26,47^{-1}$

Another barrier to condom use that emerged was the inability to negotiate condom use. About one-quarter of the FSWs in our study felt that they were in no position to negotiate condom use, as mentioned previously, ${ }^{8}$ reflecting a cultural norm that relegates females to passive positions, ${ }^{28,48,49}$ thereby weakening bargaining abilities. ${ }^{50-52}$ Gender power imbalances place females in subordinate roles and limit their options for exercising control in sexual contacts..$^{51,53}$ To implement safe sex effectively, these issues require close attention. ${ }^{25,54-56}$

Finally, trust emerged as the main barrier to safe sex with RSPs, reflecting the characteristics of intimate sexual relations where the use of condoms diminishes once a rapport is established..$^{57,58}$ None of the FSWs reported to have used condoms consistently with their RSPs, an observation that has been made previously in PNG., ${ }^{4,8,10,11}$ Although some FSWs felt that their RSPs would not intentionally infect them, others believed there was no need for condom use because trust was established. Irrespective of adequate transmission and prevention knowledge, the interpretation of a personal sense of perceived risk took a whole new meaning. ${ }^{45,59}$ This risk perception bias associated with RSPs is dangerous, as RSPs may also contribute to HIV $^{3,60}$ just as clients could. ${ }^{61}$ As FSWs are more vulnerable to HIV, areas of misperceptions that increase vulnerability must be given considerable attention when planning interventions, stressing that unsafe sex is unsafe regardless of the sexual partner and that trust does not offer protection.

Our study has a number of limitations. First, sex work is illegal in PNG and, as a result, it was impossible to obtain a random sample of FSWs. In spite of this, we were able to report on a large sample of FSWs, most of whom were participants in our existing HIV programs. Second, our findings may not represent the views of all FSWs in PNG, as we focused on FSWs in Port Moresby only, but consistent findings have been reported previously. Finally, our data were collected through focus groups; therefore, it did not allow us to collect individual stories of condom use negotiation due to the private nature of this information. Although there was a general consensus that negotiation of condom use is challenging, this would need to be explored further through one-on-one interviews.

That said, our study offers insights into the risky sexual behaviors of FSWs in Port Moresby from which programmatic decisions are recommended. Our findings highlight that safe sex practice is not determined by the availability of, access to, and promotion of condoms alone, but also by complex contextual, emotional, and other environmental factors. Until effective strategies are implemented to address these factors, no progress on HIV will be sustained. A comprehensive HIV prevention framework that seeks to work toward changing long-standing contextual factors that increase vulnerability in FSWs is required. ${ }^{3,21}$ For FSWs, the vital element is empowerment. ${ }^{21,62}$ Overall, it means inclusion of targeted efforts that invest in universal education, ${ }^{63}$ economic independence ${ }^{64,65}$ through poverty alleviation and community development schemes, ${ }^{66,67}$ sustainable livelihoods, ${ }^{62,64,68,69}$ gender equity, ${ }^{48}$ and policy reform. ${ }^{3,70}$

Furthermore, safer sex messages have reached most FSWs and they do not need to be convinced about it; however, they need to be enabled to practise it..$^{21,23,71}$ Specific behavior change programs that promote condom self-efficacy in $\mathrm{FSWs}^{34,72}$ and improve condom use in clients and $\mathrm{RSP}^{3,60}$ are required. More often than not, HIV programs rarely target clients and RSPs of FSWs, with whom the final decision for safe sex may rest. ${ }^{73-75}$ More so, research and other prevention interventions, such as health promotion, HIV testing, and treatment services, including tenofovir gel, that target these groups are long overdue. ${ }^{3}$ We recommend that these services correspond to the specific needs of clients and RSPs of FSWs, who are often overlooked under most circumstances. ${ }^{3}$ Our study shows that clients and RSPs play pivotal roles in safe sex decision making and have the power to influence the terms of the sexual practice. Males are therefore crucial to 
sustaining safe sex ${ }^{3,60,61}$ and must be targeted in programs that are gender sensitive, promote messages of safety, and mediate mutual responsibility for safe sex. ${ }^{48}$

Finally, we strongly recommend that programs must revisit the areas of misperceptions identified in this study, avoid promoting messages such as abstinence and being faithful to one uninfected sexual partner that are considered unrealistic in the context of sex work, and intensify prevention efforts on illicit drug and alcohol use for FSWs. FSWs must have the means to protect themselves within their private and commercial sexual relationships. ${ }^{42}$ Given that FSWs are the worst affected by the HIV epidemic in PNG, visible political leadership and supportive policies are required, ${ }^{3}$ without which we risk significant ramifications for the progression of HIV. We argue that HIV policies and program interventions must address these barriers, including the root causes of vulnerability.

\section{Acknowledgments}

This work was funded by the United Nations Population Fund (UNFPA) through the United Nations Joint Programme on HIV/AIDS (UNAIDS) under the Regional Unified Budget and Work-plan (UBW) grant to the budget of $[R A S / 02 / P 0]$ and implemented in collaboration with the World Vision Asia Pacific Regional Office. The authors thank the UNFPA county office staff members in Port Moresby for their support, particularly Mr Duah Owusu-Sarfo for allowing this work to be published. Our special gratitude goes to World Vision International-Asia Pacific Regional Office, particularly World Vision Pacific Developmental Group PNG for their expertise in the data collection. Most importantly, this work would not have been possible without the input of the study team, FSWs, and the invaluable advice of the National Department of Health, Port Moresby, Sexual Transmitted Infection and Research, Monitoring and Evaluation Branches. To all who contributed one way or another to this work, your efforts are appreciated.

\section{Disclosure}

The authors report no conflicts of interest in this work.

\section{References}

1. UNAIDS/WHO. Epidemiological Fact Sheet on HIV/AIDS and Sexually Transmitted Infections: Papua New Guinea 2000 Update. Geneva (Switzerland): UNAIDS/WHO; 2000.

2. UNAIDS. Sex Work and HIV/AIDS. Geneva (Switzerland): UNAIDS; 2002.

3. UNAIDS. UNAIDS Guidance Note on HIV and Sex Work. WHO Library Cataloguing-in-Publication data. UNAIDS/09.09E. Geneva (Switzerland): UNAIDS; 2009. Available from: http://www.unaids.org. Accessed 2010 Oct 19.
4. Mgone CS, Passey ME, Anang J, et al. Human immunodeficiency virus and other sexually transmitted infections among female sex workers in two major cities in Papua New Guinea. Sex Transm Dis. 2002;29(5):265-270.

5. UNAIDS/WHO/UNICEF. Epidemiological Fact Sheet on HIV and AIDS; Core Data on Epidemiology and Response. Papua New Guinea 2008 Update. Geneva (Switzerland): UNAIDS/WHO/UNICEF; 2008.

6. UNAIDS/WHO. HIV and AIDS estimates and data, 2007 and 2001. In: 2008 Report on the Global AIDS Epidemic. Geneva (Switzerland): UNAIDS/WHO; 2008. Available from: http://data.unaids.org/pub/ GlobalReport/2008/jc1510_2008_global_report_pp211_234_en.pdf. Accessed 2010 Oct 19.

7. Bruce E, Bauai L, Yeka W, et al. Knowledge, attitudes, practices and behaviour of female sex workers in Port Moresby, Papua New Guinea. Sex Health. 2010;7(1):85-86. DOI: 10.1071/SH09089.

8. Gare J, Lupiwa T, Suarkia DL, et al. High prevalence of sexually transmitted infections among female sex workers in the eastern highlands province of Papua New Guinea: correlates and recommendations. Sex Transm Dis. 2005;32(8):466-473.

9. Jenkins C. Situational Assessment of Commercial Sex Workers in Urban Papua New Guinea. A Report Prepared for the Global Programme on AIDS: Final Report. Geneva (Switzerland): WHO; 1994.

10. Morof D, Wahasoka A, Nivia H, Lupiwa T, Mgone C. Sex workers' sexual health and peer education project in Goroka, Eastern Highlands Province, Papua New Guinea. P N G Med J. 2004;47(1-2):50-64.

11. Yeka W, Maibani-Michie G, Prybylski D, Colby D. Application of respondent driven sampling to collect baseline data on FSWs and MSM for HIV risk reduction interventions in two urban centres in Papua New Guinea. J Urban Health. 2006;83 Suppl 6:i60-i72.

12. Dwyer JM, Lovell-Jones S. The gathering storm that is the HIV epidemic in Papua New Guinea. Aust N Z J Med. 1997;27(1):3-5.

13. McBride WJ. HIV/AIDS in Papua New Guinea: an unfolding disaster? Emerg Med Australas. 2005;17(4):304-306.

14. Weller SC, Davis-Beaty K. Condom effectiveness in reducing heterosexual HIV transmission. Cochrane Database Syst Rev. 2006;(2):CD003255. DOI: 10.1002/14651858.CD003255.

15. Feldblum PJ, Fortney JA. Condoms, spermicides, and the transmission of human immunodeficiency virus: a review of the literature. $\mathrm{Am} J$ Public Health. 1988;78(1):52-54.

16. Alary M, Mukenge-Tshibaka L, Bernier F, et al. Decline in the prevalence of HIV and sexually transmitted diseases among female sex workers in Cotonou, Benin, 1993-1999. AIDS. 2002; 16(3):463-470.

17. Riedner G, Hoffmann O, Rusizoka M, et al. Decline in sexually transmitted infection prevalence and HIV incidence in female barworkers attending prevention and care services in Mbeya Region, Tanzania. AIDS. 2006;20(4):609-615.

18. McNeill ET, Gilmore CE, Finger WR, Lewis JH, Schellstede WP. The Latex Condom: Recent Advances, Future Directions. Arlington (VA): Family Health International; 2008.

19. Kerrigan D, Ellen JM, Moreno L, et al. Environmental-structural factors significantly associated with consistent condom use among female sex workers in the Dominican Republic. AIDS. 2003; 17(3):415-423.

20. Ray S, van de Wijgert J, Mason P, Ndowa F, Maposhere C. Constraints faced by sex workers in use of female and male condoms for safer sex in urban Zimbabwe. J Urban Health. 2001;78(4):581-592.

21. Gupta GR, Parkhurst JO, Ogden JA, Aggleton P, Mahal A. Structural approaches to HIV prevention. Lancet. 2008;372(9640):764-775.

22. Shannon K, Strathdee SA, Shoveller J, Rusch M, Kerr T, Tyndall MW. Structural and environmental barriers to condom use negotiation with clients among female sex workers: implications for HIV-prevention strategies and policy. Am J Public Health. 2009;99(4):659-665.

23. Parker RG, Easton D, Klein CH. Structural barriers and facilitators in HIV prevention: a review of international research. AIDS. 2000; 14 Supp1 1:S22-S32. 
24. Piot P, Greener R, Russell S. Squaring the circle: AIDS, poverty and human development. PLoS Med. 2007;4(10):1571-1575. DOI: 10.1371/journal.pmed.0040314.

25. Sarkar NN. Barriers to condom use. Eur J Contracept Reprod Health Care. 2008;13(2):114-122. DOI: 10.1080/13625180802011302.

26. Nattrass N. Poverty, sex and HIV. AIDS Behav. 2009;13(5):833-840.

27. Adedimeji AA, Omololu FO, Odutolu O. HIV risk perception and constraints to protective behaviour among young slum dwellers in Ibadan, Nigeria. J Health Popul Nutr. 2007;25(2):146-157.

28. Lemeki M, Aeno H, Niva H, Yoifa S, Jenkins C. Cultural and gender factors influencing attitudes and sexual behavioural among urban youth in Eastern Highlands Province, PNG. Thirty-Ninth Annual Symposium of the Medical Society of Papua New Guinea; 2003 Sep 1-5; Mt Hagen (PNG): Medical Society of Papua New Guinea.

29. Karoline M. Knowledge, perceptions, attitudes, and practices of HIV/ AIDS: a comparative study of behavior change in commercial sex workers and truck drivers in the Dindigul and Coimbatore Districts of Tamil Nadu, India. University Center for International Studies, Department of Health Policy and Administration, The University of North Carolina at Chapel Hill; 2002.

30. Prata N, Morris L, Mazive E, Vahidnia F, Stehr M. Relationship between HIV risk perception and condom use: evidence from a population-based survey in Mozambique. Int Fam Plan Perspect. 2006;32(4):192-200.

31. Morisky DE, Chiao C, Stein JA, Malow R. Impact of social and structural influence interventions on condom use and sexually transmitted infections among establishment-based female bar workers in the Philippines. J Psychol Human Sex. 2005;17(1/2):45-63.

32. Katz C. Comprehensive models of STI/HIV/AIDS prevention for sex workers and their clients in Asia Pacific. A regional review and final evaluation report RAS/02/P09. UNFPA Country Support Team, East and South East Asia; October 2004.

33. Bruce EA, Bauai L, Keogh LA, Kaldor JM, Fairley CK. Geographical mapping and size estimation of the female sex worker population in the national capital district, Port Moresby, Papua New Guinea. Australasian Sexual Health Conference 'Diamonds and Pearls'; 2008 Sep 15-17; Perth (Western Australia): The Royal Australasian College of Physicians, Adult Medicine Division, Australasian Chapter of Sexual Health Medicine.

34. Ao T, Sam N, Manongi R, Seage G, Kapiga S. Social and behavioural determinants of consistent condom use among hotel and bar workers in Northern Tanzania. Int J STD AIDS. 2003;14(10):688-696.

35. Barrientos JE, Bozon M, Ortiz E, Arredondo A. HIV prevalence, AIDS knowledge, and condom use among female sex workers in Santiago, Chile. Cad Saude Publica. 2007;23(8):1777-1784.

36. Veller-Fornasa C, Gai F, Tarantello M, Gallina P. Knowledge of sexually transmitted diseases and condom use among female street sex workers in Padua. Acta Dermatovenoral Alp Panonica Adriat. 2005;14(3):107-110.

37. Rosenthal D, Oanha TT. Listening to female sex workers in Vietnam: influences on safe-sex practices with clients and partners. Sex Health. 2006;3(1):21-32.

38. Zellner SL. Condom use and the accuracy of AIDS knowledge in Côte d'Ivoire. Int Fam Plan Perspect. 2003;29(1):41-47.

39. Chiao C, Morisky DE, Ksobiech K, Malow RM. Promoting HIV testing and condom use among Filipina commercial sex workers: findings from a quasi-experimental intervention study. AIDS Behav. 2009;13(5):892-901.

40. Velu S, Melkote SR, Skinner EC. Factors associated with condom use among female commercial sex workers in India: a case study. Paper Presented at the Annual Meeting of the International Communication Association, Sheraton New York; 2009 May 25; New York City, NY. Available from: http://www.allacademic.com/meta/p11935_index. html. Accessed 2010 Oct 19.

41. Hesketh T, Zhang J, Qiang DJ. HIV knowledge and risk behaviour of female sex workers in Yunnan Province, China: potential as bridging groups to the general population. AIDS Care. 2005;17(8):958-966.
42. Varga CA. The condom conundrum: barriers to condom use among commercial sex workers in Durban, South Africa. Afr J Reprod Health. 1997;1(1):74-88.

43. Zulu E, Dodoo F, Ezeh A. Sexual risk taking in the slums of Nairobi, Kenya, 1993-1998. Popul Stud. 2002;56(3):311-323.

44. Keogh LA. Women's contraceptive decision-making: juggling the needs of the sexual body and the fertile body. Women Health. 2005;42(4):83-103.

45. Hulton LA, Cullen R, Khalokho SW. Perceptions of the risks of sexual activity and their consequences among Ugandan adolescents. Stud Fam Plann. 2000;31(1):35-46.

46. Kiirya KS, Kyobutungi P. Predictors of selected HIV-risk sexual behaviors in adolescents and young adults of Iganga District in Uganda: abstract no. MoPeD3972. XV International AIDS Conference; 2004 Jul 11-16; Bangkok (Thailand): The International AIDS Society.

47. Koczberski G. The sociocultural and economic context of HIV/AIDS in Papua New Guinea. Dev Bull. 2000;(52):61-63.

48. Barker G, Ricardo C, Nascimento M. Engaging Men and Boys to Transform Gender-Based Health Inequities: Is There Evidence of Impact? Geneva (Switzerland): WHO and Instituto Promundo; 2007.

49. Guilamo-Ramos V, Bouris A, Jaccard J, Lesesne C, Ballan M. Familial and cultural influences on sexual risk behaviors among Mexican, Puerto Rican, and Dominican youth. AIDS Edu Prev. 2009;21 Suppl 5:61-79.

50. Blankenship KM, West BS, Kershaw TS, Biradavolu MR. Power, community mobilization, and condom use practices among female sex workers in Andhra Pradesh, India. AIDS. 2008;22 Suppl 5:S109-S116.

51. Dunkle KL, Jewkes RK, Brown HC, Gray GE, McIntryre JA, Harlow $\mathrm{SD}$. Gender-based violence, relationship power, and risk of HIV infection in women attending antenatal clinics in South Africa. Lancet. 2004;363(9419):1415-1421.

52. Zamboni BD, Crawford I, Williams PG. Examining communication and assertiveness as predictors of condom use: implications for HIV prevention. AIDS Educ Prev. 2000;12(6):492-504.

53. Pettifor AE, Measham DM, Rees HV, Padian NS. Sexual power and HIV risk, South Africa. Emerg Infect Dis. 2004;10(11):1996-2004.

54. Chapman J, Estcourt CS, Hua Z. Saving 'face' and 'othering': getting to the root of barriers to condom use among Chinese female sex workers. Sex Health. 2008;5(3):291-298

55. Dunkle KL, Jewkes R. Effective HIV prevention requires gendertransformative work with men. Sex Transm Infect. 2007;83(3):173-174.

56. Gupta GR. How men's power over women fuels the HIV epidemic. BMJ. 2002;324(7331):183-184.

57. Murray L, Moreno L, Rosario S, Ellen J, Sweat M, Kerrigan D. The role of relationship intimacy in consistent condom use among female sex workers and their regular paying partners in the Dominican Republic. AIDS Behav. 2007;11(3):463-470.

58. Warr DJ, Pyett PM. Difficult relations: sex work, love and intimacy. Sociol Health Illn. 1999;21(3):290-309.

59. Fritz RB. AIDS knowledge, self-esteem, perceived AIDS risk, and condom use among female commercial sex workers. JAppl Soc Psychol. 2006;28(10):888-911.

60. Voeten HA, Egesah OB, Varkevisser CM, Habbema JDF. Female sex workers and unsafe sex in urban and rural Nyanza, Kenya: regular partners may contribute more to HIV transmission than clients. Trop Med Int Health. 2007;12(2):174-182.

61. Ferguson AG, Morris CN. Mapping transactional sex on the Northern corridor highway in Kenya. Health Place. 2007;13(2):504-519.

62. Bhattacharjya M. Sex Workers as Economic Agents. India: Infochange agenda; 2008 Dec 12. Available from: www.infochangeindia.org. Accessed 2010 Oct 19.

63. World Bank. Education and HIV/AIDS: A Window of Hope. Washington (DC): The World Bank; 2002.

64. Panchanadeswaran S. A literature review of the intersections between sex work, violence, alternate livelihood experiments, and HIV/AIDS in Sub-Saharan Africa, South Asia, and South-East Asia (prepared for ICRW as a background paper); 2008. 
65. UNIAIDS. The UNAIDS 2008 Report on the Global AIDS Epidemic. Geneva (Switzerland): UNAIDS; 2008.

66. IPPF, UNFPA. Make It Matter: 10 Key Advocacy Messages to Prevent HIV in Girls and Young Women. Geneva (Switzerland): IPPF, UNFPA, Young Positives and the Global Coalition on Women and AIDS; 2007.

67. Kerrigan D, Telles P, Torres H, Overs C, Castle C. Community development and HIV/STI-related vulnerability among female sex workers in Rio de Janeiro, Brazil. Health Educ Res. 2008;23(1):137-145. DOI: 10.1093/her/cym011.

68. IPPF, UNFPA. Change, Choice and Power Young Women, Livelihoods and HIV Prevention. Geneva (Switzerland): IPPF, UNFPA, Young Positives, Global Coalition on Women and AIDS; 2007.

69. Overs C. Sex workers: part of the solution. An analysis of HIV prevention programming to prevent HIV transmission during commercial sex in developing countries. 2002. Available from: http://www.who.int/hiv/ topics/vct/sw_toolkit/115 solution.pdf. Accessed 2010 Oct 19.
70. World Bank. Legal Aspects of HIV/AIDS: A Guide for Policy and Law Reform. Washington (DC): World Bank; 2007.

71. Swendeman D, Basu I, Das S, Jana S, Rotheram-Borus MJ. Empowering sex workers in India to reduce vulnerability to HIV and sexually transmitted diseases. Soc Sci Med. 2009;69(8):1157-1166.

72. Zhao R, Wang B, Fang X, Li X, Stanton B. Condom use and selfefficacy among female sex workers with steady partners in China. AIDS Care. 2008;20(7):782-790.

73. Bird ST, Harvey SM, Beckman LJ, Johnson CH; The Partners Project. Getting your partner to use condoms: interviews with men and women at risk of HIV/STDs. J Sex Res. 2001;38(3):233-240.

74. Rassjo EB, Darj E. 'Safe sex advice is good - but so difficult to follow'. Views and experiences of the youth in a health centre in Kampala. Afr Health Sci. 2002;2(3):107-113.

75. MacPhail C, Campbell C. 'I think condoms are good but, aai, I hate those things': condom use among adolescents and young people in a Southern African township. Soc Sci Med. 2001;52(11):1613-1627.
International Journal of Women's Health

\section{Publish your work in this journal}

The International Journal of Women's Health is an international, peerreviewed open-access journal publishing original research, reports, reviews and commentaries on all aspects of women's healthcare including gynecology, obstetrics, and breast cancer. Subject areas include: Chronic conditions (migraine headaches, arthritis, osteoporosis);

\section{Dovepress}

Endocrine and autoimmune syndromes; Sexual and reproductive health; Psychological and psychosocial conditions. The manuscript management system is completely online and includes a very quick and fair peer-review system. Visit http://www.dovepress.com/ testimonials.php to read real quotes from published authors. 